\title{
Investigating the Market Potential of Eco-Friendly Coal Briquettes in the Region of Tahoua, Niger
}

\author{
Issoufou Oumarou \\ Faculté de Droit d'Economie et de Gestion (FADEG) \\ Département d'Economie et de Gestion \\ Université de Tahoua PB 255 Tahoua / Niger.
}

\begin{abstract}
Since the drought of the 1970s, there is a continuous degradation of vegetal resources in Niger due to several reasons according to the environmental checking (INS, 2002). The authorities of Niger have taken to heart the issues of reforestation and deforestation. Several measures and initiatives have been taken in order to provide solutions to these issues. Given the nonexistence of credible alternatives to the use of wood as domestic energy, the measures and initiatives taken by the authorities have not produced the expected results. Through the discovery of a coal reserve in Salkadamna in the region of Tahoua (INS, 2011), an alternative to wood as domestic energy seems to be found by the Government. With the discovery of oil reserves in the extreme east of the country and with the beginning of the production at the end of 2012, natural gas became the second alternative to wood as domestic energy. In its efforts to fight deforestations the Government had taken measures and initiatives to encourage the use of natural gas as domestic energy (Hama B. , 2015). According to the Demographic and health surveys of Niger (INS, 2017), in the region of Tahoua, wood is the main source of domestic energy, it is consumed by more $97 \%$ of households. Out of this fact the government of Niger encourages the development and the use of other sources of energy. It's in this context that this study is being conducted in order to present eco-friendly coal briquettes as an alternative to wood and charcoal. The general objectives of this study are to identify potential buyers among users of wood, to determine potential demand and to develop commercialization strategies for eco-friendly coal briquettes in the city of Tahoua. To reach the above mentioned objectives, a survey is conducted among grilled meat sellers, fried food sellers and household consumers that are currently using wood charcoal or wood. In order to identify the price at which the respondents find the ecofriendly coal briquettes cheap, expensive, unaffordable, a price point analysis was used. The study then used product attributes ranking to determine which among the attributes of market available coal briquettes and wood were of greater importance to the respondents. Product usage, product attitude and image were also used in the study to analyze the data gathered through the use of market and customer behavior survey. Finally a home placement test was administered among grilled meat sellers, fried food sellers and charcoal-using households in the city of Tahoua, Niger.
\end{abstract}

Keywords (5): Eco-friendly coal briquettes; market potential, price point analysis, home placement, domestic energy

JEL Classifications: M31, O33, Q13, R21

\section{Introduction}

Since the drought of the 1970s, there is a continuous degradation of vegetal resources in Niger ${ }^{1}$ due to several reasons such as the abusive and anarchic cutting of wood for various uses including domestic energy and pharmacopoeia; the disappearance of several tree and shrub species of importance, recurring droughts, the drop in groundwater, etc. according to the environmental checking (INS, 2002). The authorities of Niger have taken to heart the issues of reforestation and deforestation. Several measures and initiatives have been taken in order to provide solutions to these issues. Many trees planting activities have been undertaken in the country in general and in Tahoua ${ }^{2}$ particularly as part of some Non-Government Organizations (NGO), Projects and Government interventions in recent years. Given the nonexistence of credible alternatives to the use of wood as domestic energy, the measures and initiatives taken by the authorities have not produced the expected results. With the discovery of a coal reserve of 92 million tons in Salkadamna in the region of Tahoua (INS, 2011), an alternative to wood as domestic energy seems to be found by the Government. It had announced in 2012 (Présidence, 2012) its intention to build coal mine with a production capacity of 1.1 million tons per year. The mine production is intended to supply fuel for a coal powered plant and to produce coal briquettes for domestic consumption.

\footnotetext{
${ }^{1}$ Republic of Niger

${ }^{2}$ Tahoua is one of eight administrative region of Niger. The capital of the region is the city of Tahoua. 
The coal briquettes plant will aim for a production of 100000 tons per year at start-up to potentially reach 300000 tons per year. Measures and initiatives are being taken by the Government to encourage the use of coal in place of wood for domestic use.

With the discovery of oil reserves in Agadem field ${ }^{3}$ in the Termit-Ténéré ${ }^{4}$ and with the oil production at the end of 2012, natural gas became the second alternative to wood as domestic energy. In its efforts to fight deforestations the Government had taken measures and initiatives to encourage the use of natural gas as domestic energy (Hama B. , 2015). The government' natural gas using campaigns succeeded in big cities like Niamey ${ }^{5}$ but failed to show tangible results in the other regions of the country. According to the Demographic and health surveys of Niger (INS, 2017), in the region of Tahoua, wood is the main source of domestic energy, it is consumed by more $97 \%$ of households. Out of this fact the government of Niger encourages the development and the use of other sources of energy. It's in this context that this study is being conducted in order to present eco-friendly coal briquettes as an alternative to wood. The eco-friendly coal briquette is a new product that was first produced and tested in 2015 . The product is made from neglected vegetable residues often thrown into the wild. The raw materials used for the production of the eco-friendly coal briquettes are among others: rice hulls, corn and peanut hulls and mostly water hyacinth. The general objectives of this study are to identify potential buyers among users of wood, determine potential demand and develop commercialization strategies for eco-friendly coal briquettes in the city of Tahoua. Specifically, the study aims to (1) present a profile and describe the behavior of the buyers of the eco-friendly coal briquettes; (2) determine qualitative requirements of the buyers and estimate the market size of the product being studied; (3) identify potential marketing opportunities, issues, and problems in meeting the demand of the buyers; and (4) formulate general strategies to address these issues and opportunities. To reach the above mentioned objectives, a survey is conducted among grilled meat sellers, fried food sellers, and household consumers that are currently using wood charcoal or wood. In order to identify the price at which the respondents find the eco-friendly coal briquettes cheap, expensive, unaffordable, a price point analysis was used. The study then used product attributes ranking to determine which among the attributes of market available coal briquettes and wood were of greater importance to the respondents. Product usage, attitude and image were also used in the study to analyze the data gathered through the use of the market and customer behavior survey. Finally a home placement test was administered among grilled meat sellers, fried food sellers and charcoal-using households in the city of Tahoua. Each respondent was given a certain quantity of eco-friendly coal briquettes to test in their homes or business for a certain period of time.

\section{Objectives of the Study}

The general objective of this study is to identify potential buyers among the following main users of wood and charcoal: the grilled meat sellers, the fried food sellers and households, to determine the potential demand and formulate commercialization strategies for the eco-friendly coal briquettes in the city of Tahoua, Republic of Niger. Specifically, this article has the ambition to (1) present a profile and describe the behavior of the buyers of the ecofriendly coal briquettes; (2) determine qualitative requirements of the buyers and estimate the market size of the product being studied; (3) identify potential marketing opportunities, issues, and problems in satisfying the demand of the buyers; and (4) formulate general strategies to address these issues and opportunities.

\section{Literature review}

Rajeev \& Homer (2004) used brand image belief in their article to experimentally examine some situational influences on the formation and consequences of two brand image beliefs, pertaining to fun and sophistication. They found that brand image beliefs have an impact only on brand purchase intentions and not on brand attitudes. Felipe \& Jéremie (2010) in their article used price point analysis to design and implement an alternative process relying on a formal forecasting model feeding a price optimization model in fast-fashion retailers such as Zara. The new process increased clearance revenues by approximately 6\%. Eun (2012) in his report used systematic framework to assess influence of social structural variables and socialization agents on consumers' product placement attitudes and purchase intentions for product placements in television shows. He found that peer communication, one of the socialization agents, has strongest relationship with for both placement-related attitudes and purchase intentions. Findings also show the associations between different demographic variables and consumers' attitudes and purchase intentions. Giorgi \& Hughes (2014) in their article used qualitative discussion groups and a quantitative online survey on 77 respondents in four locations in England, split by social grade.

\footnotetext{
${ }^{3}$ Region of Diffa in the extreme east of Niger

${ }^{4}$ an area near the border with Chad republic

${ }^{5}$ Capital of Niger
} 
They also used focus group discussion to analysis why some people act or feel a particular way rather than to provide findings that can be extrapolated to a wider population. They found that types of bags available to consumers for food shopping are varied and the combination of bag type used is often the result of a complex mixture of attitudes, behaviors and habits. In this context, around two in five of the respondents from the online panel (43\%) stated they used new plastic carrier bags for some of their purchases the last time they went food shopping. Zhang (2015) in his article used brand image to study the impact of brand image on consumer from perspective of customer equity. He also presents the shortcomings of current research and pointed out the trends for future study. Tisha et al. (2017) in their article used Focus group discussions, product attitude and image study to analyze the market potential of cacao charcoal briquettes in Los Banos, Laguna. They found that there was a very low awareness level among the respondents. They also found that the factors affecting consumers' decision were price and availability of the product.

\section{Methodology}

To reach the above stated objectives, a survey is conducted among grilled meat sellers ${ }^{6}$, fried food sellers ${ }^{7}$, and household consumers that are currently using wood charcoal and wood. In order to identify the price at which the respondents find the eco-friendly coal briquettes cheap, expensive or unaffordable a price point analysis is used. The study also used product attributes ranking to determine which among the attributes of the eco-friendly coal briquettes were of greater importance to the respondents. Product usage, attitude and image study was conducted to analyze the data gathered through the use of the market and customer behavior survey.

A survey was conducted among 125 respondents consisting of grilled meat sellers, fried food sellers and households that are currently using charcoal or fire wood. Convenience sampling was used to identify the grilled meat and fried food sellers. Based on the availability and accessibility of the respondents, 30 respondents were identified for the grilled meat sellers and 45 for the fried food market segment. Finally, 50 households' respondents were identified using purposive sampling to gauge the possibility of catering to households in the city of Tahoua, since it is estimated that 97\% of households are still active charcoal and wood users (INS, 2017).

Finally, a home placement test was administrated among the selected 30 grilled meat sellers, 45 fried food sellers and the 50 households' charcoal using respondents in the city of Tahoua. Each respondent was given a certain quantity of eco-friendly coal briquettes to test in their home or in their business. The households' respondents were given 1 kilo of eco-friendly coal briquettes each during one week; the fried food sellers were given 5 kilos each during 3 days and the grilled meat sellers 25 kilos each. Furthermore, a market and consumer survey was conducted alongside the home placement test to identify demographic characteristics, buying behaviors, and currents practices as well to establish the desired and undesired characteristics of the product and to identify the potential demand. The price point analysis was also incorporated in the survey in order to identify the price at which the respondents find the product cheap, fair, expensive or unaffordable. The Usage, Attitude and Image Study were used to analyze the data gathering through the use of the market and consumer behavior survey. The product attribute ranking was determined through the survey that was administrated after the product test. The respondents were asked to rank a specific attribute as to whether they dislike (1), somewhat dislike (2), neither like nor dislike (3), somewhat like (4), like (5) the attribute. This was used to determine which among the attributes of the eco-friendly coal briquettes were of greater importance to the respondents. The data gathering from the home placement test and consumer market survey were analyzed through the use of statistical tools. Frequency counts and percentage distributions were used to analyze the information obtained from the market and consumer behavior survey. Mean rating and rankings were used in analyzing the characteristics. Measures of central tendency, namely mean, median, and mode were also used to determine distribution of the sociodemographic characteristics of the respondents. The data gathering were then summarized to access the market potential of the eco-friendly coal briquettes in the city of Tahoua. The gathered data were finally used to formulate strategies for the commercialization of the product.

\section{Results and Discussion}

\subsection{Profile of the respondents}

Among the 30 Grilled meat sellers, 18 have their business close to Government institutions therefore their business hours are restrained during government working hours and from Monday to Friday. The 12 other have their business in residential areas, thus have business all the 7 days of the week. The respondents of this group have in average no formal education and have in average a household size of 7.6 members. The respondents also had an average income of FCFA 84,466 monthly.

\footnotetext{
${ }^{6}$ This group includes sellers of grilled whole sheep and other big quantity of grilled meat sellers

${ }^{7}$ This group includes roasted kebab, roasted fish, doughnut, barbeque and other fried of grilled food sellers 
Table 1 Socio-demographic profile of grilled meat sellers

\begin{tabular}{lllll}
\hline Variables & Average & Minimum & Maximum & Mode \\
\hline Age & 36 & 21 & 52 & 34 \\
Household size & 7.63 & 2 & 12 & 8 \\
Monthly Income (in FCFA) & 84466 & 52000 & 155000 & 60000 \\
\hline
\end{tabular}

In the case of fried food sellers, the survey revealed that the average age of the sellers is 26 and $56 \%$ have no formal education while $27 \%$ have primary school level of education and $17 \%$ have secondary level of education. The survey also showed that the average household size of this group is 7 and the monthly income is around FCFA 59,510. Concerning this group, 18 are married and 17 are either single or divorced. Also $90 \%$ of the respondents are female.

Table 2 Socio-demographic profile of fried food sellers

\begin{tabular}{lllll}
\hline Variables & Average & Minimum & Maximum & Mode \\
\hline Age & 26.31 & 18 & 52 & 20 \\
Household size & 7.17 & 3 & 12 & 8 \\
Monthly Income (in FCFA) & 59511.11 & 28000 & 150000 & 45000 \\
\hline
\end{tabular}

A total of 50 households were surveyed for the study. The average age of those interviewed was 26 years old, while the minimum and maximum ages are 18 and 52 respectively. On average, respondents were age 26 and have finished high school. The household size was mostly 7, and the monthly income is FCFA 54485. Among those surveyed, 46 of which are female while 4 are male. Moreover, $92 \%$ of the respondents are married and the remaining $8 \%$ are either divorced or single.

Table 3 Socio-demographic profile of households' respondents

\begin{tabular}{lllll}
\hline Variables & Average & Minimum & Maximum & Mode \\
\hline Age & 43,46 & 32 & 60 & 40 \\
Household size & 6.98 & 3 & 12 & 8 \\
Monthly Income (in FCFA) & 133180 & 45000 & 225000 & 160000 \\
\hline
\end{tabular}

\subsection{Buying Behavior and Frequency of Use}

The buying behavior and the frequency of use of charcoal among the respondents differ due to the difference in the nature of operations and the need of the households for charcoal. In terms of usage, the grilled meat sellers consumed an average 1 sack and half or 75 kilograms of charcoal daily. This translated to an average spending of almost FCFA 15000 daily. The fried food sellers, on the other hand, used an average of 8 kilograms daily, which cost around FCFA 1600. Lastly, household consumers used charcoal to prepare everyday meals and for special occasions such as birthday, outing, gathering, barbeque and heat water for shower during cold periods. Among the 50 respondents, $90 \%$ used charcoal on an everyday basis while the remaining $10 \%$ used charcoal only when they prepares grilled food for special occasions. In average a household consumes 1 kilogram of charcoal per use, which translates to 2 kilograms per day, and a daily cost of FCFA 400 .

In terms of sources of charcoal, most grilled meat and fried food sellers obtained their supply from suppliers in the public market. The survey also revealed that, concerning the grilled meat sellers, $30 \%$ purchase their supply daily against $20 \%$ weekly and 50\% monthly. For fried food sellers 51\% purchase their supply daily against $42 \%$ weekly and $6,6 \%$ monthly. Regarding households that use charcoal, $20 \%$ of them purchase their supply daily while $44 \%$ purchase it in a week basis, $26 \%$ on a month basis and $10 \%$ of household had no define time of purchase, they purchase charcoal when the need arises. 


\subsection{Awareness Level for the eco-friendly coal briquettes}

Fig.1 Awareness level of eco-friendly coal briquettes among the respondents

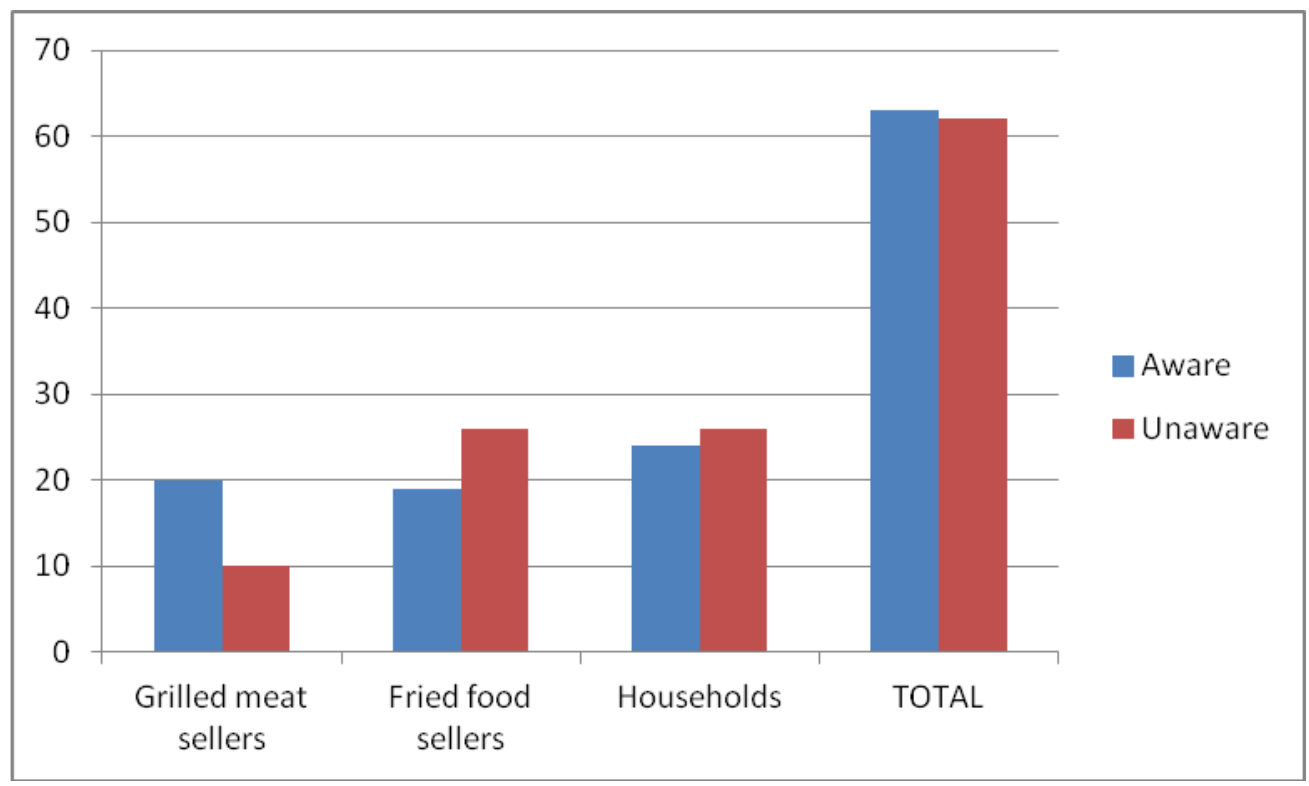

The respondents were asked if they were aware of the eco-friendly coal briquettes prior to the product test. In general, out of 125 respondents, $50.4 \%$ or 63 respondents were aware or had heard of the eco-friendly coal briquettes. From the grilled meat sellers, out of the 30 respondents 20 had heard or seen the eco-friendly coal briquettes prior to the test. In the case of fried food sellers, $42.22 \%$ of them were aware of the product, while in the case of household consumers 24 out of 50 respondents or $48 \%$ have heard of the eco-friendly coal briquettes. However, looking at the magnitude of knowledge about the eco-friendly coal briquettes, the respondents who had heard of the product do not have enough information concerning it.

\subsection{Product Attribute Analysis}

In assessing the market potential of the eco-friendly coal briquettes, it was also imperative to look at the most important product attributes that customers liked about the eco-friendly coal briquettes. The study tested six product attributes of the eco-friendly coal briquettes. The respondents were asked to rate these attributes from 1 to 5, wherein 1 represents dislike and 5 represents like. These six attributes are few ashes, absence of smoke, absence of odor, output intensity, burning time and time of ignition.

Based on the survey, grilled meat sellers, in general preferred the qualities of the eco-friendly coal briquettes in comparison with the traditional charcoal. Specifically, they liked that the eco-friendly coal briquettes did not produce smoke or odor that may affect their product. They also liked the fact that the eco-friendly coal briquettes have burning period and output intensity that are high compared with the traditional charcoal. The fried food sellers also liked the attributes of the eco-friendly coal briquettes, particularly the fact that the product did not produce too much ash and they also appreciate the absence of odor. Among the attributes, the one they dislike the most is the presence of smoke. Lastly, the household did not like much 4 of the attributes, they found that the eco-friendly coal briquettes takes too much time of ignition. They also found that the output intensity is high, thus giving them trouble in their daily cooking with a high risk of burning their food. The household nether less appreciate the absence of odor of the eco-friendly coal briquettes. 
Table 4 Product attributes rankings for the eco-friendly coal briquettes per market segment

\begin{tabular}{llll}
\hline $\begin{array}{l}\text { Mean score } \\
\text { Attributes }\end{array}$ & Grilled meat sellers & Fried food sellers & Household consumers \\
\hline Time of ignition & 4.36 & 4.22 & 3.14 \\
Burning time & 4.13 & 4.15 & 3.64 \\
Output Intensity & 4.16 & 4.02 & 2.98 \\
Absence of Smoke & 4.26 & 3.97 & 3.84 \\
Absence of Odor & 4.43 & 4.6 & 4.12 \\
Few ashes & 4.76 & 4.62 & 4.24 \\
\hline
\end{tabular}

\subsection{Price Sensitivity Analysis}

The respondents were asked about perceptions of the eco-friendly coal briquettes based on price with respect to knowledge on the current prices of wood charcoal and fire wood in the market. Two level of price were presented to the respondents, FCFA 250 per kilogram and FCFA 400 per kilogram. For the price level of FCFA 250 per kilogram, $63.33 \%$ of the grilled meat sellers, found it fair against $33.3 \%$ that found that price level cheap and $3.33 \%$ that found it expensive. On the other hand, $66.66 \%$ of the fried food sellers have found the price level fair against $13.33 \%$ and $20 \%$ that have respectively found the price cheap and expensive. Lastly $76 \%$ of the households found the price expensive. Regarding the price level of FCFA 400 per kilogram, $70 \%$ of the grilled meat sellers found the price level expensive compare with $88.88 \%$ for the fried food sellers and $92 \%$ for households.

Table 5 Eco-friendly coal briquettes price level sensitivity

\begin{tabular}{|c|c|c|c|c|c|c|}
\hline \multirow{3}{*}{ Respondents } & \multicolumn{6}{|c|}{ Price level } \\
\hline & \multicolumn{3}{|c|}{ FCFA 250 per $\mathrm{Kg}$} & \multicolumn{3}{|c|}{ FCFA 400 per $\mathrm{Kg}$} \\
\hline & Cheap & Fair & Expensive & Cheap & Fair & Expensive \\
\hline Grilled meat sellers & $33.33 \%$ & $63.33 \%$ & $3.33 \%$ & $0 \%$ & $30 \%$ & $70 \%$ \\
\hline Fried food sellers & $13.33 \%$ & $66.66 \%$ & $20 \%$ & $0 \%$ & $11,11 \%$ & $88,88 \%$ \\
\hline Households & $16 \%$ & $8 \%$ & $76 \%$ & $0 \%$ & $8 \%$ & $92 \%$ \\
\hline
\end{tabular}

\subsection{Willingness to Purchase}

Upon evaluation of the product attributes of THE eco-friendly coal briquettes versus traditional wood charcoal and wood, respondents were also asked about their willingness to purchase the eco-friendly coal briquettes if the product and the traditional charcoal are selling at the same price level. The survey revealed that out of 125 respondents, $60.74 \%$ were willing to purchase and use the eco-friendly coal briquettes while $25.25 \%$ were not willing to purchase the product. The remaining $13.99 \%$ were neutral about the eco-friendly coal briquettes. Breaking it down into segments, the survey revealed that $60.01 \%$ of grilled meat sellers were willing to purchase and use the eco-friendly coal briquettes while $23.33 \%$ were not willing to purchase the eco-friendly coal briquettes and $16.66 \%$ are neutral about the product. The respondents of the fried food sellers group, on the other hand, showed that $62.23 \%$ are willing to buy and use the product against $24.44 \%$ who were unwilling to purchase the product. $13 \%$ of this market segment is indifferent about buying or not buying the eco-friendly coal briquettes.

Lastly, $60 \%$ of the household respondents were willing to use eco-friendly coal briquettes as an alternative for wood charcoal and wood provided that the product price remains at the same level with wood charcoal since it is more economical in the sense that its burning period and fire quality are better than those of the charcoal. However $28 \%$ of those surveyed were not willing to purchase the product mostly because of the product output intensity and because they are more used to wood charcoal. Moreover $12 \%$ of the respondents remained neutral about adopting the ecofriendly coal briquettes. 
Fig.2 Respondents willingness to purchase eco-friendly coal briquettes at traditional coal price level

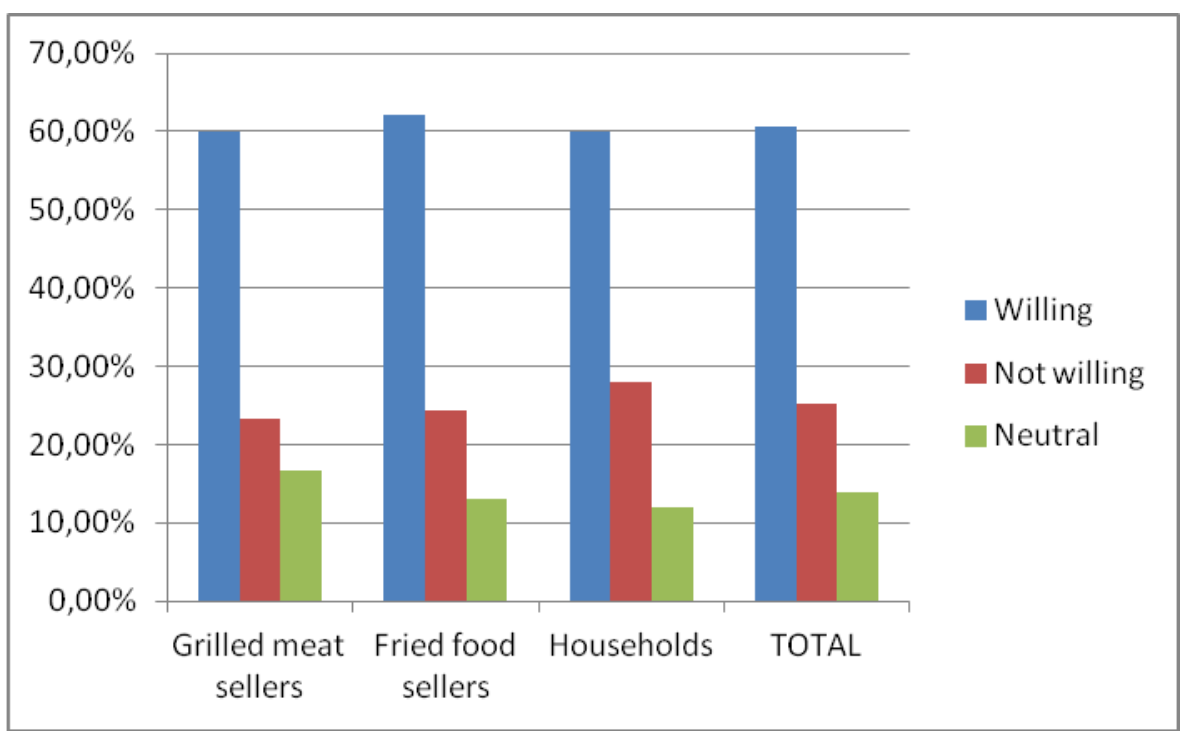

\subsection{Estimated Market potential}

Based on the computed figures and values obtained from the survey, the market potential for the eco-friendly coal briquettes in kilos was estimated and presented in the table below:

Table 6 Estimated market potential for eco-friendly coal briquettes in the city of Tahoua

\begin{tabular}{llll} 
Potential Market & Estimated demand (kilos) & Price (FCFA/kilo) & Demand value (FCFA) \\
\hline Grilled meat sellers & 324,000 & 200 & $64,800,000$ \\
Fried food sellers & 64,512 & 200 & $12,902,400$ \\
Households & 20,160 & 200 & $4,032,000$ \\
\hline
\end{tabular}

For the surveyed grilled meat sellers, there is a total of 324,000 kilos demanded by 18 established grilled meat sellers annually. Given that FCFA 200 is the price level at which these grilled meat sellers are willing to purchase the product, the estimated demand value would be FCFA $64,800,000$ per year. The surveyed showed on the other hand that the fried food sellers' market segment have an estimated demand of 64,512 kilos annually from a total of 28 established fried food sellers. Given this, there would be a total estimated demand of FCFA 12,902,400 per year.

Lastly, the estimated demand of household respondents is at 20,160 kilos per year. With the selling price of the ecofriendly coal briquettes at FCFA 200 the kilo, the demand value would be FCFA 4,032,000. Given these figures, the market segment with the most potential would be the Grilled meat sellers.

\subsection{Commercialization Strategies for eco-friendly coal briquettes}

\section{a) Strategies for grilled meat sellers}

The product attributes that the grilled meat sellers like the most are the few ashes produced, the odor of the product, the ignition time and the output intensity. Since, the grilled meat sellers consume in average 75 kilos of charcoal a day, the product intended for this market segment should be packed in sacks of 25 kilos with a seal of the brand or product name and include instructions of use. The inclusion of the product name and the brand in the packaging is important in order to distinguish the product from other type of charcoal. The instructions of use are also necessary as a guide on how to use the eco-friendly coal briquettes properly. Moreover, in order to increase the awareness of the product, it is suggested that the product be promoted through word-of-mouth. It is also suggested that the distributor of the ecofriendly coal briquettes offers a certain discount for 10 sacks of 25 kilos purchased.

\section{b) Strategies for fried food sellers}

The fried food sellers highly appreciate the fact that the product produces few ashes and the ignition time. They also like the product burning time and its output intensity. Since, the fried food sellers consume in average 8 kilos of 
charcoal a day, the product intended for this market segment should be packed in sacks of 5 kilos with a seal of the brand or product name and include instructions of use. The inclusion of the product name and the brand in the packaging is important in order to distinguish the product from other type of charcoal. The instructions of use are also necessary as a guide on how to use the eco-friendly coal briquettes. Moreover, in order to increase the awareness of the product, it is also suggested for this market segment that the product be promoted through word-of-mouth. Finally, for a start a discount should be offered for any purchase of 10 bags of 5 kilos.

\section{c) Strategies for household Consumers}

Compared with the grilled meat sellers and fried food sellers, the households respondents were not convince with the performance of the product. They found the ignition time long and also they are not satisfied with the output intensity. They indicated having trouble controlling their cooking. Nether less, they appreciate the product odor and the fact that the eco-friendly coal briquettes produce few ashes. Since this market segment use in average 2 kilos of charcoal per day, the products intended for households should be packed in bags of 2 kilos with a seal of the brand or product name and include instructions of use. The inclusion of the product name and the brand in the packaging is important in order to distinguish the product from other type of charcoal. The instructions of use are also necessary as a guide on how to use the eco-friendly coal briquettes properly. Moreover, in order to increase the awareness of the product, it is also suggested for this market segment that the product be promoted through word-of-mouth. Finally, for a start a discount should be offered for any purchase of 10 bags of 2 kilos. The eco-friendly coal briquettes should be made easily accessible by households, therefore it should be sold at the marketplace where most of the households purchase charcoal and fire wood.

\subsection{Potential Problems}

Based on the study, all three segments showed very low awareness of the product. This poses a potential problem since low awareness may result in little to no demand at all of the eco-friendly coal briquettes. In order to increase awareness about the product, an intensive and oriented marketing and advertising efforts will have to be conducted. In addition, work has to be done in order to be able to supply eco-friendly coal briquettes in large volumes.

\section{Conclusion and Recommendations}

Based on the study, all respondents showed very low awareness of the product. In order to increase awareness of the eco-friendly coal briquettes, the study recommends an intensive and oriented marketing and advertising efforts. The study also showed that respondents didn't give too much value to the fact that the eco-friendly coal briquettes are a mean to fight desertification. It came out that, even thought that respondents are concerned about desertification and climate change, it did not imply that they would purchase the product on the basis of these qualities alone. The study revealed that they gave more importance to price and attributes of the product. On this point the study recommended that the eco-friendly coal briquettes attributes be well advertised. In order to optimize the economic nature of the product, it is recommended to develop by-products such as fireplaces or firebox that will better conserve heat for cooking activities even when coal is needed. It is also recommended that specialized big ovens that use eco-friendly coal briquettes for roasting mutton, traditional bread, etc. be developed. Finally, in view of non-proven ability to produce large volume of eco-friendly coal briquettes and considering that $60 \%$ among the households surveyed showed a willingness to purchase and use the eco-friendly coal briquettes, the study recommended that the product be ameliorated regarding attributes that did not score well in the households' survey and be produced for households' use alone until large volume can be produced.

\section{References}

BACONGUIS S. (2015) Enterprise Development from Solid Waste, Home page, http://wwf.org

BALLOCCA et al. (2004) Lutte contre la désertification et gestion des ressources naturelles dans les régions de Tillaberri et Maradi, Niger (1975 - 02), Centro Citta del Terzo Mondo Working Paper n 7-2004

BURNETT J. (2000) Pricing the Product, Home page, http://www.saylor.org

CILSS (2006) Lutte contre la désertification....C'est possible, Reflets Sahéliens n ${ }^{\circ} 45$ aout - septembre -octobre ISSN $06508206,5-7$

DIOUF A. (2010) Potentiel énergétique du Niger, Home page, http://www.cridecigogne.org

DJS Research. (2014) What is a Usage and Attitude Study? Home page, http://www.marketresearchworld.net

Eun, S. K. (2012) Exploring Consumers' Attitudes and Behavior toward product placement in Television shows. Seoul: New house public communication.

Felipe , C., \& Jéremie , G. (2010) Clearance Pricing Optimization for a Fast-Fashion Retailer. 14-49. 
Giorgi, S., \& Hughes, O. (2014) Carrier bags usage and attitudes: Consumer research in England. London: Brook Lyndhurst.

Grove, P., \& Misha, S. (1996). Biomass Briquetting: Technology and Practice, Food and Agriculture Organization of the United Nations, Field Document No. 46.

HAMA B. (2015) Environnement: le Niger favorise sa production de gaz pour lutter contre l'avancée du désert et de la déforestation, Home page, http://www.news.aniamey.com/p/38340.html

HCI (2006) Invest in Niger, Home page, https://www.nigerrenaissant.org

INS (2002) Bilan environnemental, Bilan commun de Pays du Niger, 141 - 163, Home page, http://www.statniger.org/statistique

INS (2007) Industries extractives, Annuaire statistique du Niger, 217 - 218, Home page, http://www.statniger.org/statistique/index.php/publication/publications-de-l-ins/item/227-annuaires-statistiques

INS (2012) Enquête démographique et de sante et à indicateurs multiples (EDSN-MICS IV), Home page, http://www.stat-niger.org/statistique

INS (2012) Recensement général de la population et de l'habitat, Home page, http://www.stat-niger.org

INS (2015) Enquête conjointe sur la vulnérabilité à l'insécurité alimentaire des ménages au Niger, 19 - 24, Home page, http://www.stat-niger.org/statistique

INS (2017) Enquête démographique et de sante et à indicateurs multiples (EDSN-MICS V) , Home page, http://www.stat-niger.org/statistique

INS (2017) Recensement général de la population et de l'habitat, Home page, http://www.stat-niger.org

INS (2018) Fiche sur l'évolution des principaux indicateurs sociodémographiques et agrégats macroéconomiques du Niger, Home page, http://www.stat-niger.org/statistique

ISSA (2007) Programme régional de promotion des énergies domestiques alternatives au Sahel, 3 - 24, Home page, https://docplayer.fr/9195335-Programme-regional-de-promotion-des-energies-domestiques-et-alternatives-ausahel-predas.html

KAZA A. (2010) Allocution prononcée par son excellence, le général de brigade Abdou Kaza, Ministre de l'eau, de l'environnement et de la lutte contre la désertification, Home page, http://www.nigerdiaspora.net

Kent, R. (2007) Marketing Research: Approaches, Methods and Applications in Europe, Boston MA, Thomson Learning.

Kraemer, K., \& Dedrick, J. (1998) Market Potential Analysis: A Methodology for Estimating the Market Potential. University of California, Irvine Working Paper $N^{\circ}$ ITR-149.

MESUDD (2014) Cadre stratégique et la gestion durable des terres au Niger et son plan d'investissement, 13 - 50, Home page, www.foncier-developpement.fr/publication/

PDES (2017) Construction d'un complexe charbonnier à Salkadamna, Home page, http://www.nigerrenaissant.org

PDES (2017) Un Niger renaissant pour un peuple prospère, Home page, https://www.nigerrenaissant.org

Rajeev , B., \& Pamela , M. H. (2004). The Situational Impact of Brand Image Beliefs. Journal of consumer psychology , $318-330$.

ROCHETTE (1985) Déforestation et désertification au Sahel, Aménagement et nature nº 81,3 - 6

SINGH H. (2006) The Importance of Customer Satisfaction in Relation to Customer Loyalty and Retention, Asia Pacific University of Technology \& Innovation, Kuala Lumpur Working Paper $\mathrm{N}^{\circ}$ WP-06-06

SMITH S. (2011) An Introduction to Marketing Research, Home page, http://www.cloudfront.qualtrics.com

TISHA L. et al. (2017) An analysis on the market potential of cocoa charcoal briquettes in Los Banos, Languna, Philippines, Journal of Global Business and Trade vol $13 \mathrm{~N}^{\circ} 2$ november 2017, Home page, http://www.researchgate.net/publication/322890966

UNDP (2015) Emergence d'une classe moyenne et réduction des inégalités au Niger, Home page, http://www.ne.undp.org/content/niger/fr/home/library/emergence-d-une-classe-moyenne-et-reduction-desinegalites-au-ni.html

UNHCR (2016) Evaluation de référence sur l'usage des combustibles domestique dans la région de Diffa , Home page, http://www.reach1.cern.ch/reah/NER

Zhang, Y. (2015) The Impact of Brand Image on Consumer Behavior: A Literature Review. Open Journal of Business and Management, 58-62. 